\title{
Radiation Therapy for Renal Cell Carcinoma
}

\author{
Rachel Choi ${ }^{\mathrm{a}}$ and James B. Yu $\mathrm{u}^{\mathrm{a}, \mathrm{b}, *}$ \\ ${ }^{a}$ Yale School of Medicine, New Haven, CT, USA \\ ${ }^{\mathrm{b}}$ Yale Cancer Center, New Haven, CT, USA
}

Received 13 July 2018

Accepted 15 November 2018

\begin{abstract}
Radiation therapy (RT) has traditionally been disregarded in the primary or adjuvant treatment of renal cell carcinoma (RCC), but recent advances have necessitated a re-examination of the role radiation therapy may be able to play. The advent of stereotactic ablative radiotherapy (SABR), which allows for targeting of disease with higher doses in a shorter window of time, may open up new avenues for RT's role in the treatment of RCC, a cancer with a relatively low alpha/beta ratio. Thus, this review examines both the history and future of RT in the treatment of RCC with an aim to expand the discussion on treatment options for RCC.
\end{abstract}

Keywords: RT, RCC, SABR

\section{INTRODUCTION}

Renal cell carcinoma (RCC) patients will usually undergo surgical resection, often total nephrectomy, as a primary therapy, but there are still significant reasons to investigate alternative or secondary therapies for the treatment of RCC $[1,2]$. Of these reasons, the most important is that recurrence rates are significant with RCC. Recurrences tend to be metastatic, often to the lung, liver, bone, and brain, with contralateral and ipsilateral kidney recurrences both being rare unless in the case of partial nephrectomy [3]. The most common statistic for the recurrence of RCC seems to be $20-40 \%$ after surgical resection with curative intent, with late recurrence (defined as $>5$ years post-operation) in about $8.8 \%$ of patients [3-6]. (The differentiation between late and early recurrence is significant because an international, multi-center retrospective study conducted in 2013 has suggested that patients with late recurrence tend to have better cancer-associated survival compared to patients with

\footnotetext{
${ }^{*}$ Correspondence to: James B. Yu, MD, MHS, 333 Cedar St. New Haven, CT. 06520, USA. Tel.: +1 203785 5703; Fax: +1 203 785 4622; E-mail: james.b.yu@yale.edu.
}

early recurrence [6].) In addition to the risk of recurrence, surgery is not a perfect therapy option for RCC as certain patients may not necessarily benefit from it, such as patients with metastatic RCC [7]. Finally, a serious complication and adverse effect of partial and complete nephrectomy is potential worsening of or new-onset chronic kidney disease [8, 9].

There are adjuvant and alternative therapies available for patients with RCC. Systemic therapies include first-line options such as sunitinib and pazopanib which are VEGF-targeted, and later options such as mTOR inhibitors and more potent VEGF-targeted therapies [10]. Because RCC has historically been considered radioresistant, radiotherapy has not been used as a primary mode of therapy in modern medicine. The National Comprehensive Cancer Network (NCCN) writes specifically, "Adjuvant radiation therapy (RT) after nephrectomy has not shown benefit, even in patients with nodal involvement or incomplete tumor resection." [11] A recent 2017 New England Journal of Medicine (NEJM) review of systemic therapies for metastatic RCC (mRCC) only briefly mentions radiotherapy as a potential option for palliative care for RCC [10]. However, it also mentions that stereotactic ablative 
radiotherapy (SABR) may be useful in certain cases, and SABR is indeed a new, cutting-edge option in RCC treatment [10]. A 2018 Nature review focuses on SABR as it suggests that radiotherapy may "move towards the forefront of RCC treatment." [12] The purpose of our review is to investigate the role of RCC in the context of this new technology, and to critically examine past research regarding radiotherapy as a treatment option for RCC.

\section{HISTORICAL RATIONALE AGAINST USE OF RT FOR RCC}

Similar to how surgical intervention for RCC encompasses risks for renal failure and dysfunction, radiation treatment for kidneys holds the potential for permanent decline in renal function and toxicity. The proximity of the kidneys to small bowel and other abdominal organs makes radiotherapy more difficult as well, given the sensitivity of the small bowel to radiotherapy.

Historically, RCC has been considered to be relatively radioresistant compared to other types of cancer. This is largely based on a 1996 meta-analysis evaluated the in vitro radiosensitivity of isolated cancer cell types [13]. Specifically, in this study by Deschavanne et al., the authors analyzed survival curves following radiation of 674 cell lines that were found in the body of literature at the time and found that RCC had the highest survival at 2 Gy compared to other cell lines [13]. Since that study, more contemporary analysis of the radiosensitivity of presumed non-sensitive cell lines (such as melanoma) has revealed the picture to be much more complex [14].

However, studies about the use of radiotherapy for RCC do exist, and merit some critical review. RT has been used preoperatively, postoperatively, and intraoperatively (with regards to surgical resection) for the treatment of RCC. The following sections review research regarding each of these uses.

Preoperative use of RT before radical nephrectomy has generally shown a non-statistically significant impact on patients in clinical trials. In 1973, a prospective randomized study of 126 patients showed that patients receiving a 30-Gy total dose of radiation (in a low dose per fraction) before radical nephrectomy did not show any significant benefit in terms of 5-year overall survival [15]. When cases were stratified by clinical characteristics, however, patients with tumor-infiltrating veins and/or lymph vessels did better in overall survival duration, complete surgical resection, and frequency rate of metastases [15]. However, these results were not conclusive enough for the authors to suggest the use of RT for patients with localized RCC [15]. In 1977, a similar study with a cohort of 88 patients undermined even the minimally beneficial results of the first study, as the patients receiving RT were found to have lower 5-year overall survival rates and stratification did not reveal any beneficial effects of the preoperative RT [16]. Since then, a small retrospective study at Mayo Clinic in 1994 showed that there may be a benefit for patients who have local recurrence of RCC to undergo preoperative and intraoperative RT combined with surgical debulking, but as the study included only 11 patients it is not particularly powerful [17]. One caveat to all these studies is that they were performed with radiation techniques that are obsolete in the present day. With advances in treatment planning, delivery, patient immobilization, image guidance, as well as improved identification and delineation of tumor extent, it is likely that outcomes from modern radiation treatment would be much improved compared to treatments delivered decades ago.

Intraoperative radiation therapy (IORT) is theoretically advantageous due to the direct visualization of the tumor bed, as well as direct application of radiation to the tumor without unnecessary radiation of organs that would otherwise be in between the tumor and the entry and exit beams of higher energy linear accelerator treatment. In 1998, a small single-center retrospective study showed a role for IORT in this way, with less dose limitation than with preoperative or postoperative use [18]. In this study of 11 patients, gastrointestinal toxicity was low and the research group observed no IORT-specific late adverse effects [18]. A more recent study looking at patients treated with IORT between 1985 and 2010 suggested that improved disease-specific survival may be possible with IORT [19]. Another study yielded favorable results for patients treated with intraoperative electron radiation therapy (IOERT) followed by external beam radiation therapy (EBRT), where this was shown to improve local control (although not overall survival rates) for patients with locally recurrent RCC [20]. Overall, the use of intraoperative RT to attain better local control in RCC patients seems promising, but requires more research.

Finally, postoperative radiation treatment for RCC aims to deliver ablative doses of radiation to residual tumor. A meta-analysis by Tunio et al. looks at the impact of postoperative RT on overall survival, 


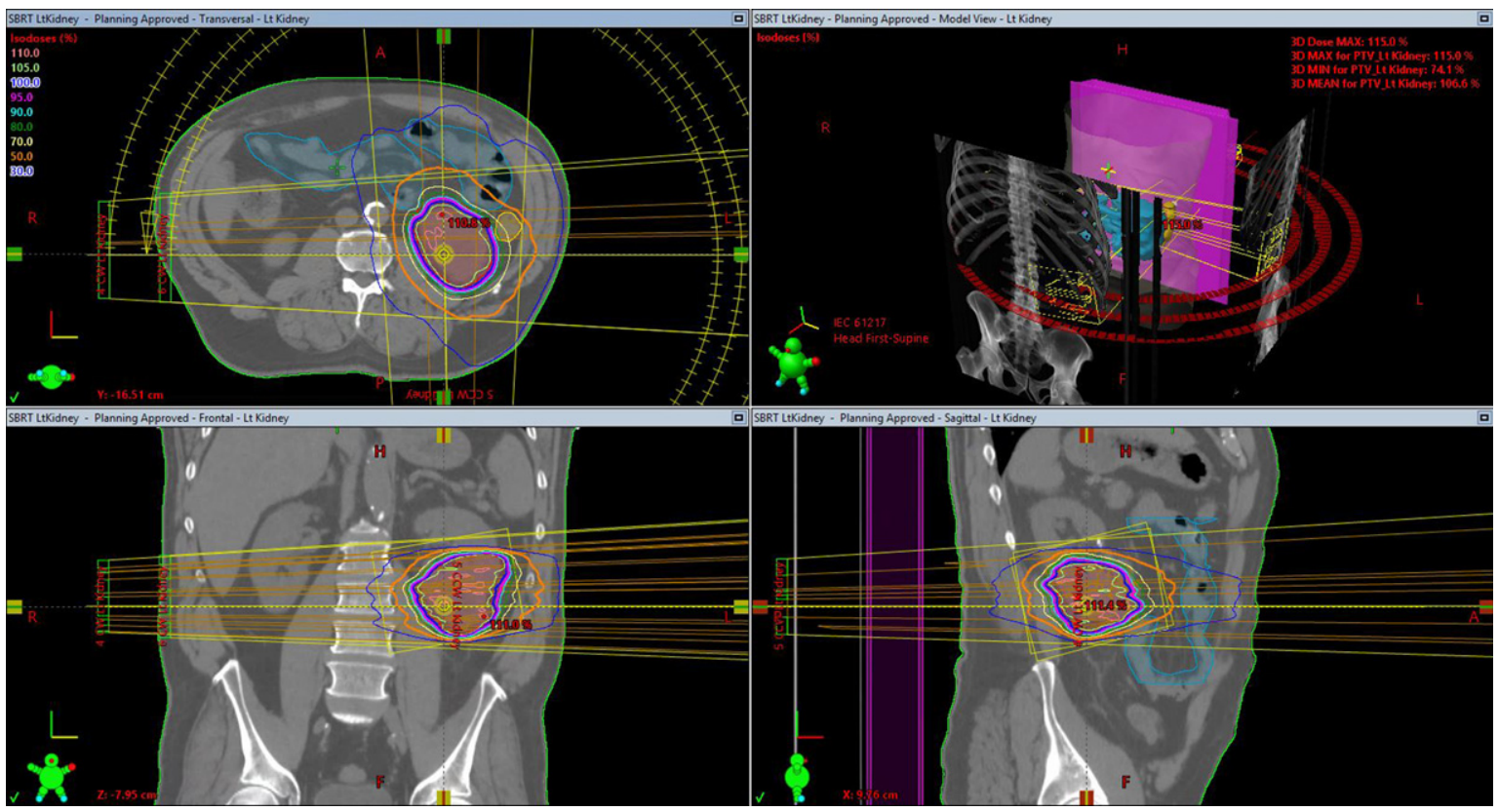

Fig. 1. Example of a patient treated with SABR for a renal tumor.

disease-free survival, and local failure from studies in the late 1900s [21]. Tunio et al. found that when analysis was conducted for the total pool of 735 patients from the seven controlled trials they were reviewing, postoperative radiotherapy was successful in reducing local failure, but not in improving overall survival or disease-free survival [21]. The improvement in local failure is important, as some patients may be more susceptible to local failure, even after total resection of the tumor. This includes patients with perinephric fat extension, positive margins, and gross residual disease [22]. An important aspect of this analysis, in which the authors included both randomized controlled trials and retrospective studies if they were "well-controlled", was that only the retrospective studies showed a benefit of postoperative radiotherapy [21]. The two prospective studies that were included, one from 1973 and one from 1987, showed that postoperative radiotherapy offered neither a survival nor a relapse benefit to the patients $[23,24]$. In fact, high rates of GI toxicities were observed with post-operative RT use, making it an even less attractive option [22]. Overall, the metaanalysis did not show conclusive support for a role of postoperative radiotherapy in treatment of RCC, especially when considering additional limitations of the study such as non-standardized treatment dosage, technique, and follow-up periods [20].

\section{RATIONALE FOR RCC TREATMENT WITH MODERN RT}

Although the review of studies above does not show conclusive support for the use of radiotherapy in the treatment of RCC, new recommendations may be warranted given recent technological advances. In particular, aspects of RT that have changed and may be important for treatment of RCC in the future include single-fraction and multi-fraction SABR, the synergy of radiotherapy with immunotherapy, and improved radiation treatment planning.

As mentioned previously, SABR has the potential to deliver high radiation doses with greater precision than older radiotherapy techniques. Using multiple overlapping and often intensity modulated beams or arcs (Fig. 1), SABR uses modern computing power and patient immobilization to optimize radiotherapy treatment.

The most important question to ask with any new radiotherapy technique being considered for the treatment of RCC is whether it may be at least partially successful in overcoming the previouslythought inherent radioresistance of RCC. One thing that is known about RCC is that the alpha/beta ratio of RCC is considered to be low, meaning that RCC is relatively more sensitive to larger fraction, or dose, sizes [25]. As others have suggested, this may make it 
Table 1

Currently-Recruiting Clinical Trials for treatment of RCC with SBRT in the U.S. (as of October 2018, from clinicaltrials.gov)

\begin{tabular}{|c|c|c|c|c|}
\hline $\begin{array}{l}\text { NCT } \\
\text { Number }\end{array}$ & Title & Phase & Study Type & Sponsor \\
\hline NCT02306954 & $\begin{array}{l}\text { Study of High Dose Interleukin-2 (IL-2) and } \\
\text { Stereotactic Body Radiation (SBRT) in } \\
\text { Patients With Metastatic Renal Cancer }\end{array}$ & Phase 2 & Interventional & $\begin{array}{l}\text { Providence Health \& Services } \\
\text { Prometheus Laboratories } \\
\text { Cytokine Working Group }\end{array}$ \\
\hline NCT03065179 & $\begin{array}{l}\text { Trial of SBRT in Combination With } \\
\text { Nivolumab/Ipilimumab in RCC / Kidney } \\
\text { Cancer Patients }\end{array}$ & Phase 2 & Interventional & $\begin{array}{l}\text { University of Texas } \\
\text { Southwestern Medical Center }\end{array}$ \\
\hline NCT02542202 & $\begin{array}{l}\text { Stereotactic Body Radiation Therapy in } \\
\text { Treating Patients With Metastatic or } \\
\text { Recurrent Kidney Cancer }\end{array}$ & N/A & Interventional & $\begin{array}{l}\text { University of Chicago } \\
\text { National Cancer Institute }\end{array}$ \\
\hline NCT03575611 & $\begin{array}{l}\text { Study of Stereotactic Body Radiation } \\
\text { Therapy for Oligometastatic Renal Cell } \\
\text { Carcinoma }\end{array}$ & N/A & Interventional & $\begin{array}{l}\text { MD Anderson Cancer Center } \\
\text { Cancer Prevention Research } \\
\text { Institute of Texas }\end{array}$ \\
\hline NCT02141919 & $\begin{array}{l}\text { Stereotactic Ablative Body Radiation } \\
\text { Therapy for Patients With Primary Renal } \\
\text { Cancer }\end{array}$ & Phase 2 & Interventional & $\begin{array}{l}\text { University of Texas } \\
\text { Southwestern Medical Center }\end{array}$ \\
\hline NCT01890590 & $\begin{array}{l}\text { A Phase II Study of Cyberknife } \\
\text { Radiosurgery for Renal Cell Carcinoma }\end{array}$ & N/A & Interventional & $\begin{array}{l}\text { Beth Israel Deaconess } \\
\text { Medical Center } \\
\text { Dana-Farber Cancer Institute }\end{array}$ \\
\hline NCT02782715 & $\begin{array}{l}\text { PII SBRT+Microwave } \\
\text { Ablation in Renal Cell Carcinoma }\end{array}$ & $\begin{array}{l}\text { Phase } 1 \\
\text { Phase } 2\end{array}$ & Interventional & $\begin{array}{l}\text { University of Wisconsin, } \\
\text { Madison } \\
\text { National Cancer Institute }\end{array}$ \\
\hline NCT02781506 & $\begin{array}{l}\text { Nivolumab and Stereotactic Ablative } \\
\text { Radiation Therapy (SAbR) for Metastatic } \\
\text { Clear Cell Renal Cell Carcinoma }\end{array}$ & Phase 2 & Interventional & $\begin{array}{l}\text { University of Texas } \\
\text { Southwestern Medical Center }\end{array}$ \\
\hline NCT02581384 & $\begin{array}{l}\text { Stereotactic Body } \\
\text { Radiotherapy (SBRT) for Pulmonary } \\
\text { Metastases in Ewing Sarcoma, } \\
\text { Rhabdomyosarcoma, and Wilms Tumors }\end{array}$ & $\begin{array}{l}\text { Phase } 1 \\
\text { Phase } 2\end{array}$ & Interventional & Dana-Farber Cancer Institute \\
\hline NCT02170181 & $\begin{array}{l}\text { Clinical Registry for Oligometastic Disease, } \\
\text { Consolidation Therapy, Debulking Prior to } \\
\text { Chemotherapy, or Re-Irradiation }\end{array}$ & N/A & Observational & $\begin{array}{l}\text { University of Texas } \\
\text { Southwestern Medical Center }\end{array}$ \\
\hline NCT03693014 & $\begin{array}{l}\text { A Study of Several Radiation Doses for } \\
\text { Patients With Progression on } \\
\text { Immunotherapy/Checkpoint Inhibitors }\end{array}$ & Phase 2 & Interventional & $\begin{array}{l}\text { Memorial Sloan Kettering } \\
\text { Cancer Center }\end{array}$ \\
\hline
\end{tabular}

an ideal disease to target with SABR, which involves higher doses in a short amount of time [26]. However, it is also important to keep in mind that the alpha/beta ratio does not factor in the potential for serious adverse events or side effects, and that this must also be balanced in determining a patient's treatment plan.

In 2017, Siva et al. conducted a pooled metaanalysis of 223 SABR patients from 5 countries, including the United States and Canada [27]. The analysis showed that SABR was able to achieve good local control, at a rate of $97.8 \%$ at 2-year and 4-year time-points [27]. This local control rate is aligned with a pooled analysis from 2012 of SABR patients, which yielded a local control rate of $94 \%$ [28]. In terms of efficacy, the 2017 pooled analysis showed that both single-fraction SABR and multifraction SABR were effective in improving local control, but that single-fraction SABR may be more beneficial for distant progression and overall survival [27]. Another major result of this study was that SABR may be associated with improved renal function, as 52 patients experienced improved estimated glomerular filtration rates post-procedure, which was not an expected outcome [27]. Finally, a major advantage of SABR for RCC patients is that the procedures may limit toxicities to other organs. The 2017 analysis showed that of the 223 patients, only 3 patients experienced grade 3 and 4 toxicities [27]. In a separate study, looking specifically at the safety of SABR for RCC extracranial metastases, researchers also reported a favorable safety profile, where grade 3 toxicities were observed in 8 of 84 total patients treated with SABR [29].

Another emerging field of research for difficult-totreat cancers is the combination of immunotherapy 
with radiotherapy [30-32]. For metastatic RCC, mTOR or VEGF inhibition are the current standard of treatment [33]. Although the purpose of this review is not to analyze immunotherapy for RCC, it is mentioned because one potential benefit of new radiotherapy techniques like SABR may be that the radiotherapy can be immunomodulatory and ultimately improve clinical responses [34]. Of particular interest is how the abscopal effect, where local radiotherapy can have off-target effects and also help reduce distant metastases, may be T-cell-mediated $[35,36]$. Currently, clinical trials are ongoing, such as one at the University of Texas Southwestern Medical Center that combines Stereotactic Body Radiation Therapy (SBRT) with Nivolumab/Ipilimumab for RCC patients (NCT03065179), as well as others (NCT02318771, NCT02599779, NCT01884961, NCT01896271) [30]. (A full table of currentlyrecruiting SBRT trials for the treatment of RCC in the U.S. is provided in Table 1.) Hopefully more data should be available in the near future about the efficacy and safety of such regimens.

Finally, with new technologies has come a need for better treatment planning for both primary RCC and its metastases. While the CT is the gold standard for radiotherapy treatment planning in general, this may have to be reconsidered for RCC treatment planning. In a 2017 retrospective study looking at the comparison of MRI and CT for the delineation of bone metastases in metastatic RCC, the authors found that in all of 9 patient cases, the gross tumor volumes (GTV) were at least as large on MRI as they were in CT [37]. In multiple cases, the gross tumor volumes were larger on MRI than on CT [37]. There was a significant difference in median gross tumor volume between MRI and CT, where median GTV on MRI was $33.4 \mathrm{~mL}$, compared to $18.1 \mathrm{~mL}$ on CT [37]. These findings suggest that a new standard for radiotherapy treatment planning may have to be considered as CT may underestimate tumor volumes. MRI based treatment will also allow for targeting of disease that extends into soft tissue that would otherwise be missed by CT based planning. Finally, modern MRI-linac technology now allows for adaptive planning of treatment based on changes in MRI tumor characteristics that were otherwise undetectable with CT based imaging. Potentially, treatment volumes can be reduced as the tumor responds to treatment, allowing for lower doses of radiation to surrounding normal tissue as well as escalation of dose to tumor or even within-tumor targets.

\section{CURRENT RECOMMENDATIONS AND REVIEWS}

In conclusion, although multiple past bodies of research suggest that RT may not be useful for treatment of RCC, modern advances, particularly in SABR, warrant a new evaluation of RT in the treatment of RCC. Thus, although the NCCN does not currently involve RT as part of the standard of care for RCC [11], it is a topic that will need to be further discussed periodically as technologies advance. Most recent studies have focused on the potential role of RT in treating metastases of RCC to other sites, particularly the bone [38, 39]. However, we propose that the role of RT, specifically SABR, should be examined and evaluated by the NCCN for the following: treatment of residual disease in the kidney, treatment of previously inoperable RCC, and adjuvant treatment of disease that is at high risk for local dissemination beyond typical nephrectomy beds $[40,41]$.

\section{CONFLICTS OF INTEREST}

JBU reports research funding from 21st Century Oncology, and consulting fees from Augmenix Inc., outside of the presented work. RC has no financial conflicts of interest.

\section{REFERENCES}

[1] Shinder BM, et al. Surgical Management of Advanced and Metastatic Renal Cell Carcinoma: A Multidisciplinary Approach. Front Oncol. 2017;7.

[2] Lattouf JB, Trinh QD, Saad F. The contemporary role of surgery in kidney cancer. Curr Oncol. 2009;16:S8-S15.

[3] Janzen NK, Kim HL, Figlin RA, Belldegrun AS. Surveillance after radical or partial nephrectomy for localized renal cell carcinoma and management of recurrent disease. Urol Clin North Am. 2003;30:843-52.

[4] Chin AI, Lam JS, Figlin RA, Belldegrun AS. Surveillance Strategies for Renal Cell Carcinoma Patients Following Nephrectomy. Rev Urol. 2006;8:1-7.

[5] Lam JS, Leppert JT, Belldegrun AS, Figlin RA. Novel approaches in the therapy of metastatic renal cell carcinoma. World J Urol. 2005;23:202-12.

[6] Brookman-May SD, et al. Time to recurrence is a significant predictor of cancer-specific survival after recurrence in patients with recurrent renal cell carcinomaresults from a comprehensive multi-centre database (CORONA/SATURN-Project). BJU Int. 2013;112:909-16.

[7] Méjean A, et al. Sunitinib Alone or after Nephrectomy in Metastatic Renal-Cell Carcinoma. N Engl J Med. 0, null. 2018.

[8] Satasivam P, et al. Patients with medical risk factors for chronic kidney disease are at increased risk of renal impair- 
ment despite the use of nephron-sparing surgery. BJU Int. 2015;116:590-5.

[9] Choi S-K, Song C. Risk of Chronic Kidney Disease After Nephrectomy for Renal Cell Carcinoma. Korean J Urol. 2014;55:636-642.

[10] Choueiri TK, Motzer RJ. Systemic Therapy for Metastatic Renal-Cell Carcinoma. N Engl J Med. 2017;376:35466.

[11] Motzer RJ, et al. Kidney Cancer, Version 2.2017, NCCN Clinical Practice Guidelines in Oncology. J Natl Compr Canc Netw. 2017; 15:804-34.

[12] Siva S, et al. Radiotherapy for renal cell carcinoma: Renaissance of an overlooked approach. Nat Rev Urol. 2017;14:549-63.

[13] Deschavanne PJ, Fertil B. A review of human cell radiosensitivity in vitro. Int J Radiat Oncol. 1996;34:251-66.

[14] Rutter CE, et al. Demonstration of differential radiosensitivity based upon mutation profile in metastatic melanoma treated with stereotactic radiosurgery. J Radiosurg SBRT. 2016;4:97-106.

[15] van der Werf-Messing B. Proceedings: Carcinoma of the kidney. Cancer. 1973;32:1056-61.

[16] Juusela H, Malmio K, Alfthan O, Oravisto KJ. Preoperative irradiation in the treatment of renal adenocarcinoma. Scand J Urol Nephrol. 1977;11:277-81.

[17] Frydenberg M, Gunderson L, Hahn G, Fieck J, Zincke H. Preoperative External Beam Radiotherapy Followed by Cytoreductive Surgery and Intraoperative Radiotherapy for Locally Advanced Primary or Recurrent Renal Malignancies. J Urol. 1994;152:15-21.

[18] Eble MJ, Staehler G, Wannenmacher M, [The intraoperative radiotherapy (IORT) of locally spread and recurrent renal-cell carcinomas]. Strahlenther Onkol Organ Dtsch Rontgengesellschaft Al. 1998;174:30-6.

[19] Paly JJ, et al. Outcomes in a multi-institutional cohort of patients treated with intraoperative radiation therapy for advanced or recurrent renal cell carcinoma. Int J Radiat Oncol Biol Phys. 2014;88:618-23.

[20] Habl G, et al. Intraoperative electron radiation therapy (IOERT) in patients with locally recurrent renal cell carcinoma. Radiat Oncol Lond Engl. 2013;8:282.

[21] Tunio MA, Hashmi A, Rafi M. Need for a new trial to evaluate postoperative radiotherapy in renal cell carcinoma: A meta-analysis of randomized controlled trials. Ann Oncol. 2010;21:1839-45.

[22] Rabinovitch RA, Zelefsky MJ, Gaynor JJ, Fuks Z. Patterns of failure following surgical resection of renal cell carcinoma: Implications for adjuvant local and systemic therapy. J Clin Oncol Off J Am Soc Clin Oncol. 1994;12: 206-12.

[23] Kjaer M, et al. A Randomized Trial of Postoperative Radiotherapy Versus Observation in Stage II and III Renal Adenocarcinoma. Scand J Urol Nephrol. 1987;21:285-9.

[24] Finney R. The Value of Radiotherapy in the Treatment of Hypernephroma-a Clinical Trial. Br J Urol. 45:258-69.

[25] Ning S, Trisler K, Wessels BW, Knox SJ. Radiobiologic studies of radioimmunotherapy and external beam radiotherapy in vitro and in vivo in human renal cell carcinoma xenografts. Cancer. 1997;80:2519-28.

[26] Swaminath A, Chu W. Stereotactic body radiotherapy for the treatment of medically inoperable primary renal cell carcinoma: Current evidence and future directions. Can Urol Assoc J. 2015;9:275-80.

[27] Siva S, et al. Pooled analysis of stereotactic ablative radiotherapy for primary renal cell carcinoma: A report from the International Radiosurgery Oncology Consortium for Kidney (IROCK). Cancer. 124:934-42.

[28] Siva S, Pham D, Gill S, Corcoran NM, Foroudi F. A systematic review of stereotactic radiotherapy ablation for primary renal cell carcinoma. BJU Int. 2012;110:E737-743.

[29] Wang CJ, et al. Safety and Efficacy of Stereotactic Ablative Radiation Therapy for Renal Cell Carcinoma Extracranial Metastases. Int J Radiat Oncol Biol Phys. 2017;98:91-100.

[30] Kang J, Demaria S, Formenti S. Current clinical trials testing the combination of immunotherapy with radiotherapy. J Immunother Cancer. 2016;4:51.

[31] Tang C, et al. Combining Radiation and Immunotherapy: A New Systemic Therapy for Solid tumors? Cancer Immunol Res. 2014;2:831-8.

[32] Thamm DH. Interactions between radiation therapy and immunotherapy: The best of two worlds? Vet Comp Oncol. 2006;4:189-97.

[33] Ljungberg B, et al. EAU guidelines on renal cell carcinoma: The 2010 update. Eur Urol. 2010;58:398-406.

[34] De Wolf K, Vermaelen K, De Meerleer G, Lambrecht BN, Ost $\mathrm{P}$. The potential of radiotherapy to enhance the efficacy of renal cell carcinoma therapy. Oncoimmunology. 2015;4.

[35] Frey B, et al. Induction of abscopal anti-tumor immunity and immunogenic tumor cell death by ionizing irradiation - implications for cancer therapies. Curr Med Chem. 2012;19:1751-64.

[36] Demaria $\mathrm{S}$, et al. Ionizing radiation inhibition of distant untreated tumors (abscopal effect) is immune mediated. Int J Radiat Oncol Biol Phys. 2004;58:862-70.

[37] Prins FM, et al. Superior target delineation for stereotactic body radiotherapy of bone metastases from renal cell carcinoma on MRI compared to CT. Ann Palliat Med. 2017;6:S147-S154

[38] Grünwald V, et al. An interdisciplinary consensus on the management of bone metastases from renal cell carcinoma. Nat Rev Urol. 2018;15:511-21.

[39] Altoos BM, et al. Is RCC truly radioresistant? Local control rates of metastatic renal cell carcinoma (RCC) to the lung using stereotactic radiotherapy (SBRT). J Clin Oncol. 2015;33:445.

[40] Hallemeier CL, et al. Long-term outcomes after maximal surgical resection and intraoperative electron radiotherapy for locoregionally recurrent or locoregionally advanced primary renal cell carcinoma. Int J Radiat Oncol Biol Phys. 2012;82:1938-43.

[41] Nikolaev A, Benda R, Palliative Radiation Therapy for Symptomatic Control of Inoperable Renal Cell Carcinoma. Urol Case Rep. 2015;4:51-2. 